\title{
Sphingolipid metabolism in type 2 diabetes and associated cardiovascular complications
}

\author{
JING SUI ${ }^{1}$, MINGQIAN HE ${ }^{2}$, YUE WANG ${ }^{2}$, XINRUI ZHAO ${ }^{3}$, YIZHI HE ${ }^{4}$ and BINGYIN SHI $^{2}$ \\ ${ }^{1}$ Department of Endocrinology and International Medical Center; ${ }^{2}$ Department of Endocrinology, The First Affiliated \\ Hospital of Xi'an Jiaotong University, Xi'an, Shaanxi 710061; ${ }^{3}$ Department of Immunology and Rheumatology, \\ The Second Affiliated Hospital of Xi'an Jiaotong University, Xi'an, Shaanxi 710004; \\ ${ }^{4}$ Department of Endocrinology, Xi'an No. 3 Hospital, Xi'an, Shaanxi 710018, P.R. China
}

Received March 23, 2019; Accepted August 1, 2019

DOI: $10.3892 /$ etm.2019.7981

\begin{abstract}
Sphingolipid metabolism is dysregulated in type 2 diabetes mellitus (T2DM); however, the focus of previous studies was mostly limited to ceramide (Cer), and only few studies have investigated other metabolites, including sphingosine-1 phosphate (So1P). The present study aimed to examine the involvement of 8 major sphingolipid metabolites, including Cer, glucosyl ceramide (GluCer), lactosyl ceramide (LacCer), sphingomyelin (SM), sphinganine (Sa), SolP, sphingosine (So) and sphinganine-1-phosphate (Sa1P), during the progression of T2DM, and to evaluate the ability of serum sphingolipids to predict cases of diabetes with an elevated risk of cardiovascular complications. Blood samples were obtained from 245 participants who were divided into 3 groups: Healthy controls, pre-diabetes (pre-DM) and diagnosed diabetes. The 8 major sphingolipid metabolites were measured by high-performance liquid chromatography-tandem mass spectrometry and blood parameters were determined by routine laboratory assays for all subjects. Among the sphingolipid metabolites, SolP was associated with sex and lean mass index, but not with the body mass index. SolP was highest in healthy controls and gradually decreased when the disease proceeded to pre-DM and T2DM. GluCer, SM, Sa and So decreased in pre-DM and rose again in T2DM, graphically exhibiting a ' $U$ ' shape change during the progression of diabetes. So1P and Sa were identified to be significantly associated with cardiovascular complications by multivariate logistic regression analysis. Receiver operating characteristic curve analysis also suggested that So1P and Sa were able to indicate cardiovascular complications in diabetic patients. Pre-DM and diabetes were significantly associated with decreased So1P, SM, Sa and So, compared with the healthy controls. SolP was correlated with the progression
\end{abstract}

Correspondence to: Professor Bingyin Shi, Department of Endocrinology, The First Affiliated Hospital of Xi'an Jiaotong University, 277 Yanta West Road, Xi'an, Shaanxi 710061, P.R. China E-mail: shibingy@126.com

Key words: type 2 diabetes, cardiovascular complications, sphingolipid metabolism, sphingosine-1-phosphate of T2DM, and was a predictor of an elevated risk of cardiovascular complications among T2DM patients, along with Sa. The present study was registered with ClinicalTrials.gov (no. NCT02826759; April 2016).

\section{Introduction}

Diabetes places a continuous burden on public health worldwide, partially attributable to the global rise in obesity and a sedentary lifestyle. Its prevalence in adults has doubled in the past 35 years. An estimated 3.7 million deaths were caused by diabetes, or its associated complications, in 2012, and it is estimated by the World Health Organization (WHO) to become the 7th leading cause of mortality by 2030 (1). Type 2 diabetes mellitus (T2DM) accounts for the majority of cases, and is also an independent risk factor for macrovascular complications, including cardiovascular disease (CVD), particularly for females (2). CVD is the leading cause of morbidity and mortality for individuals with diabetes and results in $30 \%$ of all deaths, with this figure expected to increase in the next 10 years (2,3). Although the underlying mechanisms through which diabetes increases the likelihood of CVD remain to be fully elucidated, abundant evidence has assured an association between these two factors, beginning with the Framingham study (1). Of note, eliminating obesity and unhealthy diets, in addition to increasing physical activity can prevent $\sim 80 \%$ of heart disease, stroke, and diabetes mellitus (2). Therefore, it is essential to identify patients with an elevated risk of CVD, and individuals who present with CVD may also benefit from early intervention to avoid recurrences. The present study aimed to identify a marker linked to the progression of diabetes and distinguish individuals with T2DM with an elevated risk for CVD.

Sphingolipids are a class of lipids sharing a backbone of sphingoid bases, which have diverse effects on diabetes, cancer and CVD at the intra- and extracellular level. Sphingoanine (Sa) is produced by the conjugation of the amino acid serine with the fatty acid palmitoyl coenzyme A (CoA) in the presence of a rate-limiting enzyme (serine palmitoyl transferase; SPT), and is then further converted into dihydroceramide. After dehydrogenation, the key intermediate of the sphingolipid biosynthetic pathway, ceramide (Cer), is formed. Once 
Cer is transferred from the endoplasmic reticulum to the Golgi complex by specialized carrier proteins, different types of complex sphingolipids are generated, including sphingomyelin (SM), lactosyl ceramides (LacCer), sphingosine (So) and sphingosine-1-phosphate (So1P). It has been indicated that sphingolipids have a role in glucose homeostasis and metabolic disorders (4). In diabetic patients, an accumulation of adipose sphingolipids compared with that in body mass index (BMI)-matched non-diabetic individuals was detected $(5,6)$. Saturated fatty acids, including palmitate, may stimulate the aforementioned sphingolipid biosynthetic pathway, which partly explains why increased sphingolipid levels were observed in patients with metabolic syndrome and obesity (7). Furthermore, upregulation of Cer is associated with insulin resistance, as a reversal of insulin resistance was achieved when SPT was inhibited in a murine model of obesity (8). It was underscored that conversion of the elevated Cer to SolP is critical to improving insulin resistance and cardiac dysfunction (9). SolP also has important roles in vasoconstriction and vasorelaxation through different endothelial cell receptors, and appears to be involved in thrombosis and hemostasis (10). An inverse association between atherosclerotic disease and SolP has been validated in humans (11). Another member of the sphingolipid family, plasma SM, was reported to be correlated with CVD, although this has not been widely confirmed. Of note, the current knowledge of sphingolipid metabolism in the field of diabetes and CVD is limited.

Therefore, the present study aimed to explore sphingolipid metabolism during the progression of T2DM, and to investigate whether sphingolipids may serve as biomarkers for the progression of diabetes and as indicators for an elevated risk of CVD in patients with diabetes.

\section{Materials and methods}

Subjects. A total of 408 Chinese patients admitted to the First Affiliated Hospital of Xi'an Jiaotong University (Xi'an, China) between January 2016 and January 2017 were recruited to investigate the sphingolipid metabolite profiles (mean age at recruitment, $47.1 ; 60.4 \%$ males). The different groups were matched for age, sex and BMI. The exclusion criteria were liver or kidney failure and coagulant disorders. A total of 69 patients who had these disorders or missing laboratory/clinical data were excluded. Thus, the final study population consisted of 202 patients with T2DM, 25 individuals with pre-diabetes (pre-DM) and 112 healthy controls who underwent a yearly health examination (all patients were aged 18-80 years). Peripheral blood samples were drawn at the initial medical examination, in the morning after a fast of at least $8 \mathrm{~h}$, and immediately stored at $-80^{\circ} \mathrm{C}$ until the sphingolipid measurements were performed. To rule out the potential influence of platelet activity, sex, age and BMI on the concentration of sphingolipids, participants were instructed not to smoke, perform any intensive physical activity or take any medication, including aspirin, prior to blood collection. The cohort was sex-, age- and BMI-matched. The present study complied with the Declaration of Helsinki and was approved by the Ethics Committees of the First Affiliated Hospital of Xi'an Jiaotong University (Xi'an, China). The participants enrolled in the study provided written informed consent.
Diagnostic criteria. A waist circumference (WC) $\geq 90 \mathrm{~cm}$ in males and $\geq 85 \mathrm{~cm}$ in females is defined as central obesity according to the guidelines of the Chinese Joint Committee for Developing Chinese Guidelines (12). According to the Working Group on Obesity in China, $24 \mathrm{~kg} / \mathrm{m}^{2} \leq \mathrm{BMI}<28 \mathrm{~kg} / \mathrm{m}^{2}$ and $\mathrm{BMI} \geq 28 \mathrm{~kg} / \mathrm{m}^{2}$ are considered as overweight and obesity, respectively (13). T2DM was diagnosed if any of the following criteria were satisfied: i) Fasting plasma glucose (FPG) $\geq 7.0 \mathrm{mmol} / \mathrm{l}$; ii) $2 \mathrm{~h}$ plasma glucose $(2 \mathrm{hPG}) \geq 11.1 \mathrm{mmol} / \mathrm{l}$; iii) glycated hemoglobin (HbAlc) level $\geq 6.5 \%$; iv) random plasma glucose $\geq 11.1 \mathrm{mmol} / \mathrm{l}$ plus symptoms of hyperglycemia; v) T2DM diagnosed previously. Pre-DM was defined as follows: FPG $\geq 5.6-6.9 \mathrm{mmol} / 1$ or $2 \mathrm{hPG} 7.8-11.0 \mathrm{mmol} / 1$ or $\mathrm{HbAlc}$ 5.7-6.4\%. In the present study, diabetes-associated cardiovascular complications referred to ischemic heart disease, either newly diagnosed on admission or already noted in medical records, excluding stroke and peripheral disease. Hypertension was defined as systolic blood pressure $>140 \mathrm{mmHg}$, diastolic blood pressure $>90 \mathrm{mmHg}$, or self-reported use of anti-hypertensive medication. Cigarette smoking was defined as the consumption of at least 100 cigarettes in a patient's lifetime.

Clinical parameters. Blood pressure, WC, hip circumference (HC), body weight and body height were measured by a trained physician, following the standard protocol set by the WHO. The values of these parameters were averaged from three measurements. The BMI was calculated as weight over height squared $\left(\mathrm{kg} / \mathrm{m}^{2}\right)$. Body fat (BF) was estimated by using the Clínica Universidad de Navarra-Body Adiposity Estimator equation (14) and validated in a large population. $B F \%=-44$ $.988+(0.503 \times$ age $)+(10.689 \times$ sex $)+(3.172 \times$ BMI $)-(0.026 \times$ $\left.\mathrm{BMI}^{2}\right)+(0.181 \times \mathrm{BMI} \times \mathrm{x}$ sex $)-(0.02 \times \mathrm{BMI} \times \mathrm{x}$ age $)-\left(0.005 \times \mathrm{BMI}^{2}\right.$ $\mathrm{x}$ sex $)+\left(0.00021 \mathrm{x} \mathrm{BMI}^{2} \mathrm{x}\right.$ age $)$, where male $=0$ and female $=1$ for sex, and age was entered in years. The cut-off points for $\mathrm{BF}$ in the present study were as follows: $\mathrm{BF}$ tertile $1,<28.31 \%$; $\mathrm{BF}$ tertile 2, 28.31-34.18\%; $\mathrm{BF}$ tertile $3,>34.18 \%$. The lean mass index (LMI) was calculated as follows: $\mathrm{LMI}=(1-\mathrm{BF}) \mathrm{x}$ BMI. As there is still no reference of the LMI for the Chinese population, the cut-off points for three equal groups in the final study population were calculated (tertile $1,<15.91 \mathrm{~kg} / \mathrm{m}^{2}$; tertile $2,15.91-18.22 \mathrm{~kg} / \mathrm{m}^{2}$; tertile $3,>18.22 \mathrm{~kg} / \mathrm{m}^{2}$ ). HbAlc, high- and low-density lipoprotein cholesterol, triglycerides (TG), total cholesterol and uric acid were assessed by the clinical laboratory of the First Affiliated Hospital of Xi'an Jiaotong University (Xi'an, China) according to the standardized assay protocols.

Extraction and measurement of sphingolipids. Blood samples were centrifuged at $200 \mathrm{x}$ g for $10 \mathrm{~min}$ at $4^{\circ} \mathrm{C}$. Serum was aliquoted in $1.5-\mathrm{ml}$ tubes and stored at $-80^{\circ} \mathrm{C}$ until sphingolipid assays were performed. Sphingolipid measurements were performed according to a previously published protocol (15). A total of $40 \mu 1$ serum was extracted using methanol/chloroform (17:83). Subsequently, Cer, GluCer, LacCer, SM, Sa, Sa1P, So, So1P and each internal standard (Avanti Polar Lipids) were analyzed by high-performance liquid chromatography-tandem mass spectrometry.

Statistical analysis. Continuous data are presented as the mean \pm standard deviation. The Student's t-test and 
Kruskal-Wallis test were applied to compare parameters between two groups and among multiple groups, respectively. Categorical variables are expressed as the frequency and percentage, and the Chi-square test, or Fisher's exact test when appropriate, were used. Univariate and multivariate logistic regression model analyses were performed to identify the relevant sphingolipid metabolites in patients with T2DM. Receiver-operator characteristic (ROC) curve analysis was applied for certain sphingolipid metabolites in order to determine the predictive ability for patients at higher risk of CVD. The ROC curves displayed the sensitivity vs. 1-specificity values, and the area under the ROC curve was provided. Two-sided P-values of $<0.05$ were considered to indicate statistical significance. Statistical analysis was performed with SPSS statistical software 25.0 (IBM Corp.). Scatter plots were created using GraphPad Prism 6.0 (GraphPad Software, Inc.).

\section{Results}

Serum sphingolipidomic analyses in healthy controls. Sex, age and body composition have been previously reported to be associated with certain sphingolipids, including So and Cer, in various diseases. Therefore, the effects of age, sex and four parameters commonly used to represent the body composition, i.e. central obesity, BMI, LMI and BF, on the concentration of serum sphingolipids were analyzed in 112 healthy controls to rule out any potential confounding factors. These patients were 22-76 years of age (mean age, $45.7 \pm 12.9$ years) without either hypertension or dyslipidemia, and about half of them were females (Table SI). In addition, a significant association between SolP and sex was identified (Fig. 1). Serum So1P in male participants was about two times as high as that in female patients (So1P in males; $5.67 \pm 0.08 \times 10^{-2} \mathrm{ng} / \mathrm{ml}$; and in females, $\left.2.57 \pm 0.05 \times 10^{-2} \mathrm{ng} / \mathrm{ml} ; \mathrm{P}<0.01\right)$. However, no significant differences were observed in serum sphingolipids between the different age groups in the healthy controls (Fig. S1). The BMI was not associated with the serum concentration of the 8 analyte sphingolipids (Fig. S2). BF was significantly associated not only with Cer (tertile $1,4.26 \pm 3.03 \times 10^{-2} \mathrm{ng} / \mathrm{ml}$; tertile 2, $3.26 \pm 2.57 \times 10^{-2} \mathrm{ng} / \mathrm{ml}$; tertile $3,6.56 \pm 5.04 \times 10^{-2} \mathrm{ng} / \mathrm{ml} ; \mathrm{P}<0.05$ tertile 2 vs. 3), but also with SM (tertile 1, 37.39 $\pm 16.87 \mathrm{ng} / \mathrm{ml}$; tertile 2, $46.85 \pm 24.84 \mathrm{ng} / \mathrm{ml}$; tertile 3, $59.69 \pm 37.27 \mathrm{ng} / \mathrm{ml}$; $\mathrm{P}<0.05$, tertile 1 vs. 3; Fig. 2). Furthermore, Cer was associated with central obesity $(\mathrm{P}<0.01$; Fig. 3$)$ and LMI was positively associated with So1P (tertile 1, $1.67 \pm 1.44 \times 10^{-2} \mathrm{ng} / \mathrm{ml}$; tertile 2, $4.27 \pm 3.94 \times 10^{-2} \mathrm{ng} / \mathrm{ml}$; tertile $3,4.82 \pm 3.26 \times 10^{-2} \mathrm{ng} / \mathrm{ml} ; \mathrm{P}<0.01$, tertile 1 vs. 3 ; Fig. 4 ).

Alterations of serum sphingolipid metabolites during the progression of T2DM. Next, the serum concentrations of sphingolipid metabolites in three groups of sex- and body composition parameter-matched participants were assessed. Table I presents the clinical characteristics of the study subjects. The patients with pre-DM and DM had higher HbA1c, FPG and TG levels compared with those of the healthy controls. There were no significant differences in BMI, BF, TC and LDL-C among the three groups, there was a clear graphical ' $U$ ' shape change in the concentrations of GluCer, SM and Sa during the development from a healthy condition to pre-DM and finally to T2DM (Fig. 5).
Concentrations of these three metabolites were always the lowest in patients with pre-DM, and slightly increased in patients with T2DM, while they were highest in the healthy controls, except for GluCer. GluCer was higher in T2DM group compared with healthy controls $(\mathrm{P}<0.01)$ and pre-DM $(\mathrm{P}<0.05)$. So1P levels in the healthy controls were higher compared with T2DM $(\mathrm{P}<0.001)$ and pre-DM $(\mathrm{P}<0.01)$. Sa levels in the healthy controls were higher compared with T2DM $(\mathrm{P}<0.01)$ and pre-DM $(\mathrm{P}<0.001)$. SM $(\mathrm{P}<0.01)$ and So $(\mathrm{P}<0.05)$ levels were higher in the healthy controls compared with T2DM (Fig. 5). Of note, SolP was also highest in the healthy controls, but gradually decreased as the disease proceeded instead of exhibiting the ' $U$ ' shape change. This suggests that these metabolites, particularly So1P, may be associated with the progression of T2DM and may serve as biomarkers for evaluating the severity of T2DM.

SolP and Sa act as biomarkers for the severity of diabetes. Evaluation of complications is a method for assessing the severity of T2DM with a long-term view. Therefore, one cohort of T2DM patients without any diabetes-associated complications and another cohort of T2DM patients with cardiovascular complications, who were sex- and body dimension parameter (BMI, BF, LMI and central obesity) -matched, were recruited. The baseline characteristics of the 85 patients included in the two groups are presented in Table II. There was no significant difference between the groups in terms of sex, BMI, BF, LMI or central obesity; only blood pressure and FPG were significantly different. As expected, SM, Sa, SolP and So were significantly decreased in T2DM patients with cardiovascular complications compared with those in T2DM patients without cardiovascular complications $(\mathrm{P}=0.01$, $\mathrm{P}<0.001, \mathrm{P}<0.05$ and $\mathrm{P}<0.05$, respectively; Table III). To exclude potential confounding factors, these four metabolites were included in subsequent univariate and multivariate logistic regression analyses, which indicated that Sa and So1P were independent variables for distinguishing between T2DM with and without cardiovascular complications $(\mathrm{P}<0.05$ and $\mathrm{P}<0.05$, respectively; Table III).

ROC analysis was also used to evaluate the diagnostic performance of Sa and So1P in the differentiation between simple T2DM and T2DM with cardiovascular complications (Fig. 6). Similar results were observed in So1P and Sa, the area under the ROC curve (AUC) for So1P was $0.744(\mathrm{P}=0.003)$, whilst the AUC for Sa was $0.824(\mathrm{P}<0.001)$. This suggest that Sa and So1P may be able to significantly distinguish patients with an elevated risk of cardiovascular complications among patients with T2DM. Another relatively short-term index for evaluating the management of T2DM is HbA1c. A cohort of 94 T2DM patients stratified by HbA1c was recruited. The subjects were mostly middle-aged and had similar lipid profiles whilst $\mathrm{HC}$ and $\mathrm{BF}$ showed significant differences among groups $(\mathrm{P}<0.05$; Table IV). Significant alterations in SolP were identified among diabetic patients with different glucose managements as stratified by HbA1c levels $(\mathrm{P}=0.05$, $\mathrm{HbA1c}>9 \%$ vs. HbA1c<7\%; Fig. S3). To conclude, So1P and Sa were able to identify patients with an elevated risk of cardiovascular complications among T2DM patients So1P was also significantly associated with the progression from pre-DM to T2DM. 

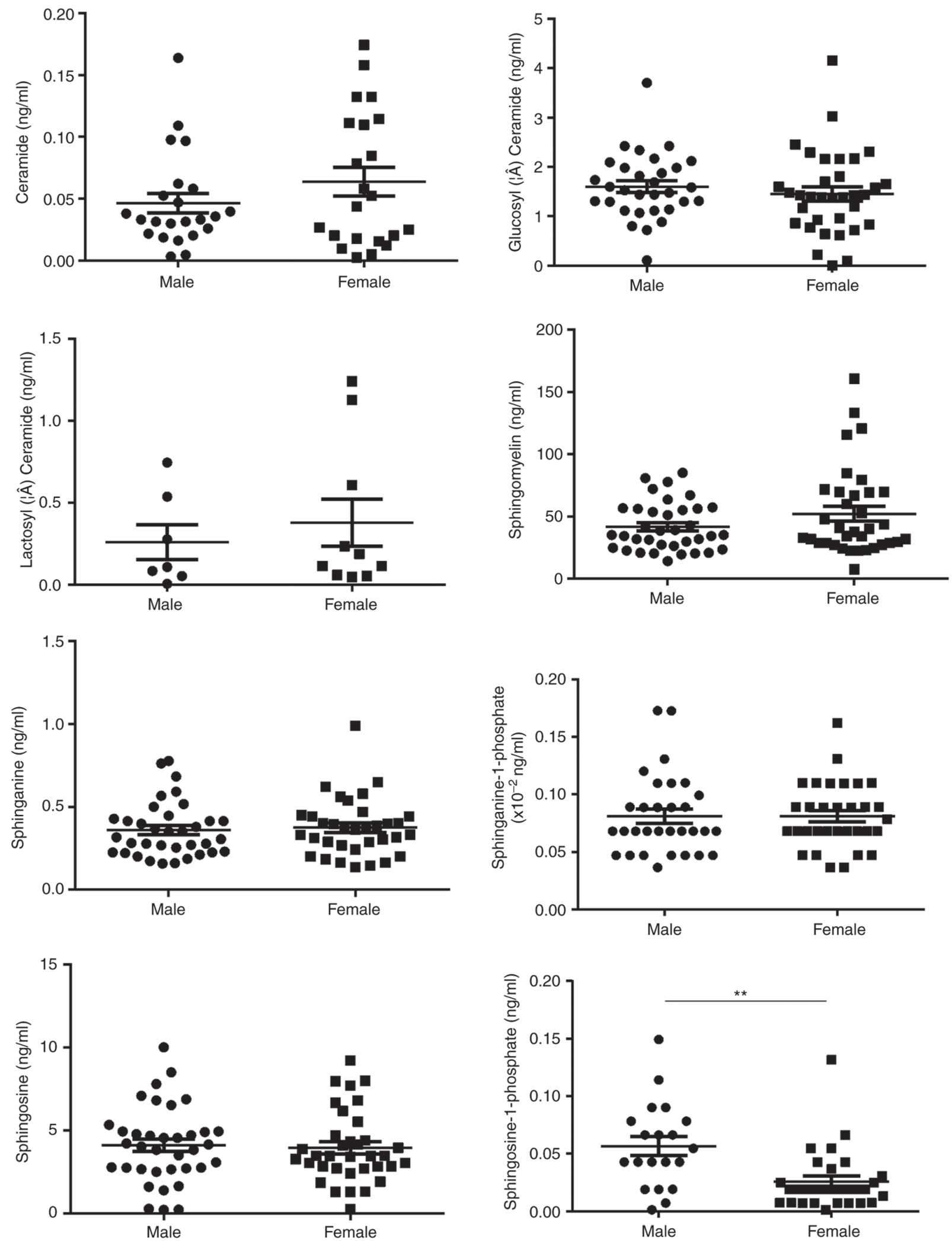

Figure 1. Sphingolipid metabolites in healthy controls stratified by sex. A significant association between Sphingosine -1 phosphate and sex was identified. ${ }^{* * *} \mathrm{P}<0.01$.

\section{Discussion}

Several studies in mouse models and humans have linked sphingolipid metabolites with metabolic disorders $(16,17)$ and atherosclerosis $(18,19)$. However, to date, the sphingolipid profile of diabetic patients with CVD has remained to be investigated. Thus, the present study was designed to explore alterations in the serum sphingolipids profile in patients with pre-DM, T2DM and healthy controls in order to identify potential novel biomarkers for the early diagnosis of patients 

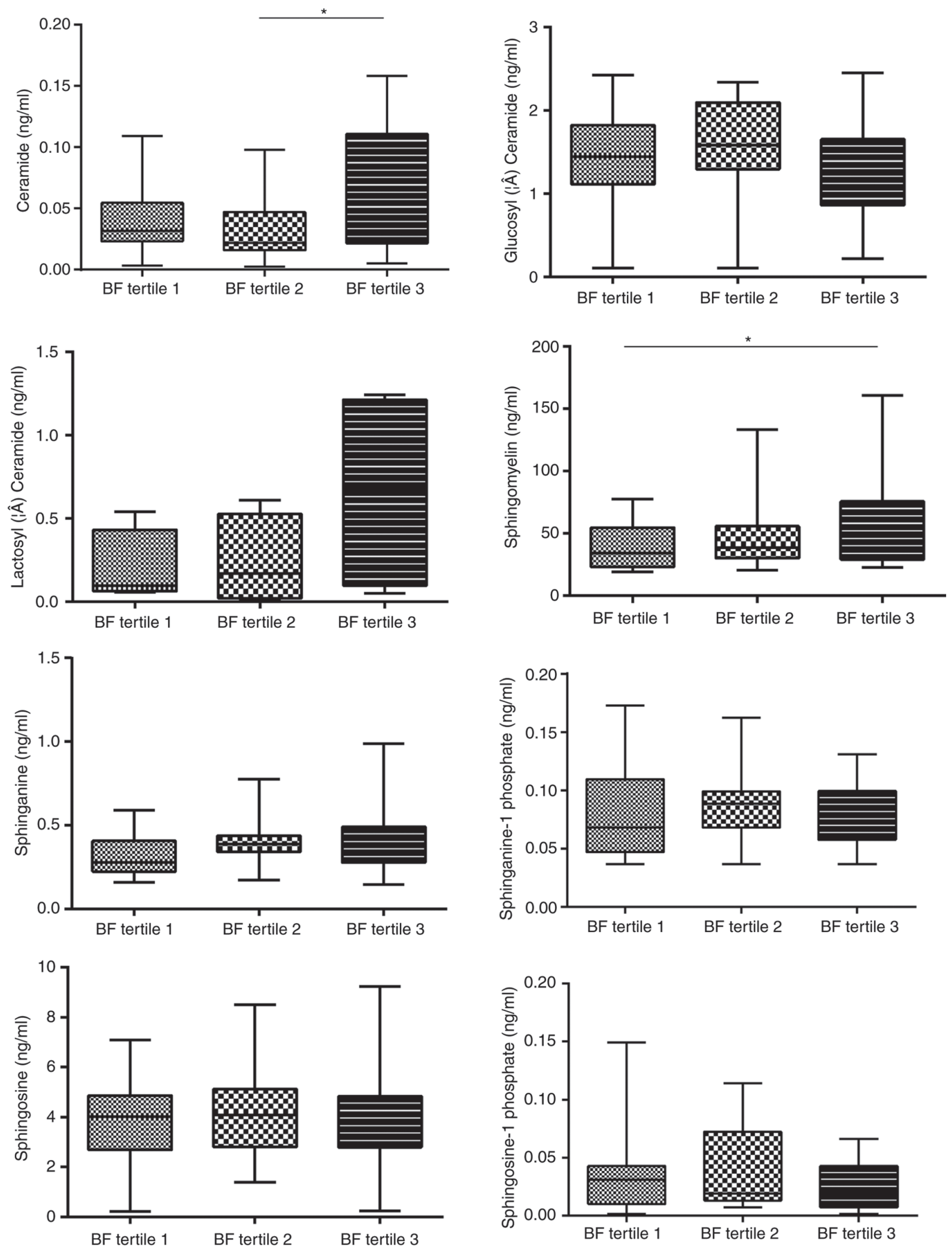

Figure 2. Sphingolipid metabolites in healthy controls stratified by body fat. Body fat was significantly associated not only with Ceramide ( $\mathrm{P}<0.05$, tertile 2 vs. tertile 3), but also with Sphingomyelin. ("P<0.05, tertile 1 vs. tertile 3$)$.

with T2DM at an elevated risk for cardiovascular complications. In the present study, 8 major sphingolipid metabolites, namely SM, So, Sa, So1P, Sa1P, Cer, GluCer and LacCer, which occur in the metabolic pathway of sphingolipids, were measured (20). The major results of the present study were as follows: i) In healthy controls, several serum sphingolipids were significantly associated with sex but not with age. In terms of body measurements, the LMI, central obesity and BF, but not the BMI, were associated with sphingolipids; ii) SolP was significantly correlated with the progression from pre-DM 

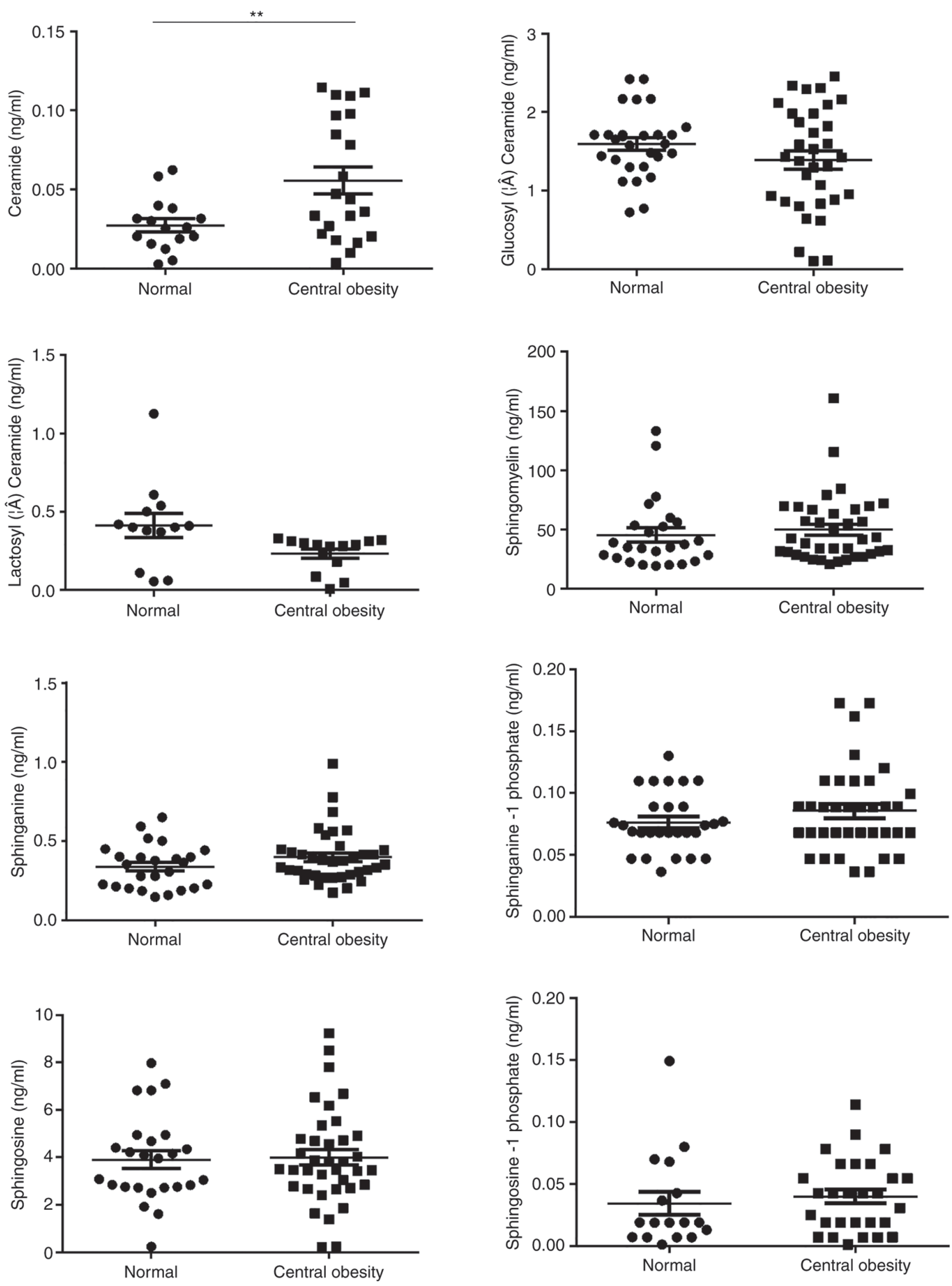

Figure 3. Sphingolipid metabolites in healthy controls stratified by the absence/presence of central obesity. Ceramide was significantly associated with central obesity. ${ }^{* *} \mathrm{P}<0.01$

to T2DM; iii) So1P and Sa were indicated to be biomarkers for diabetic patients at an elevated risk for cardiovascular complications.
Cer has been confirmed to be involved in the pathogenesis of DM, and is elevated in adipocyte tissues and skeletal muscle of obese humans (21) and C57BL/6J mice on a high-fat diet. 

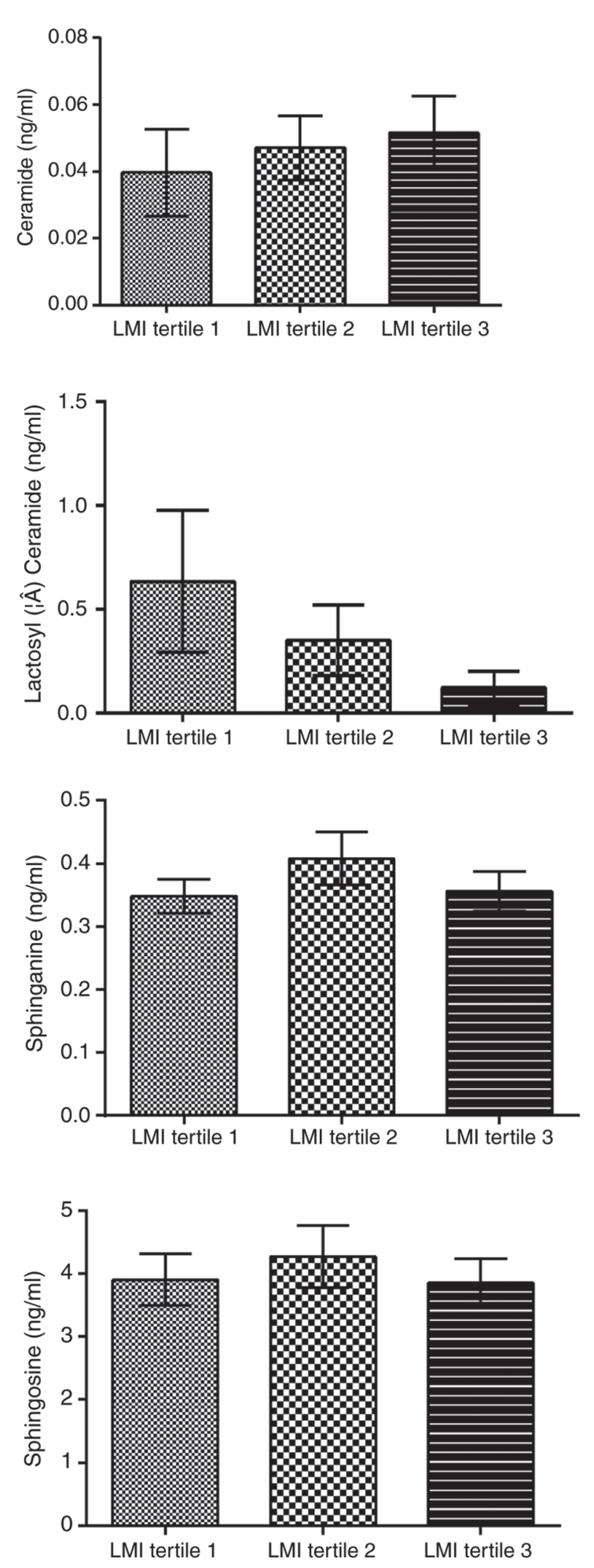
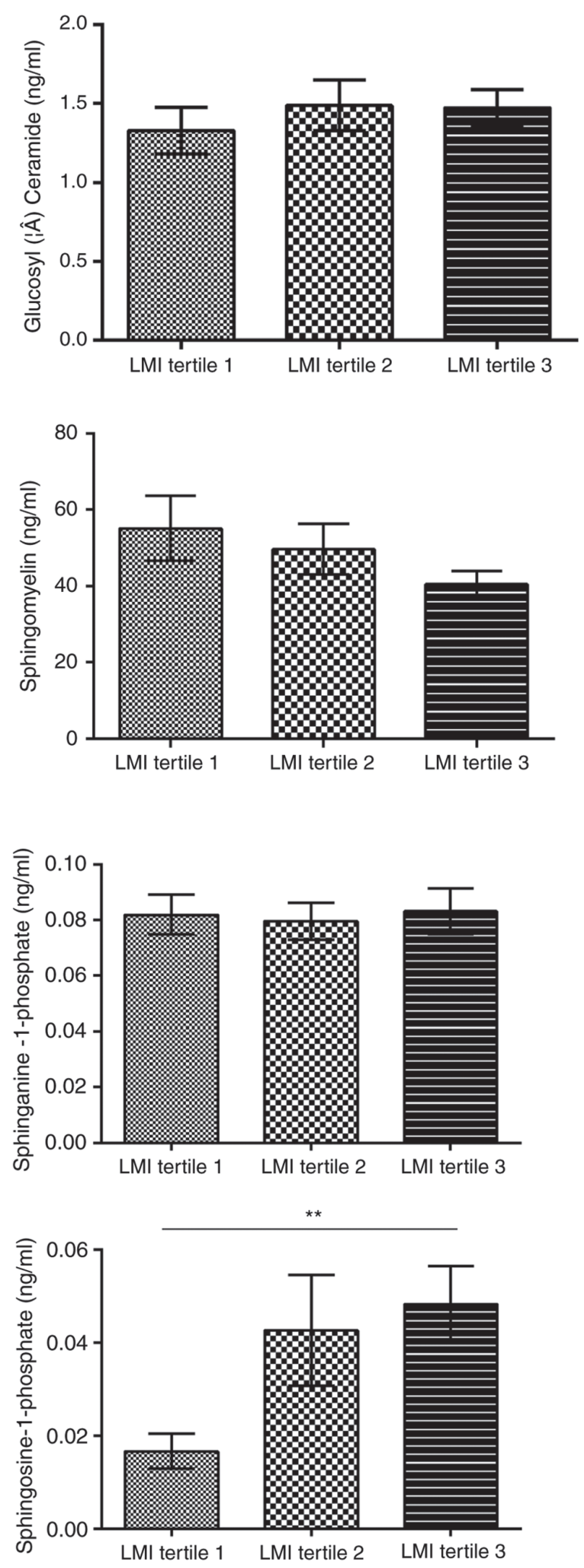

Figure 4. Sphingolipid metabolites in healthy controls stratified by LMI. LMI was positively associated with Sphingosine-1 phosphate. ${ }^{* *} \mathrm{P}<0.01$, tertile 1 vs. tertile 3 . LMI, lean mass index.

This effect was rescued in CerS6-deficient mice (22). In accordance with prior experiments, the present study indicated that Cer was significantly associated with BF and central obesity; in other words, Cer accumulated in individuals with obesity. However, this trend was not significant in terms of BMI and LMI, which may be due to the different methods used to reflect the body composition, while the association between Cer and obesity is consolidated.

SolP is well known for its bioactive properties, namely its pro-cell survival, anti-apoptotic, immune cell trafficking, glucose homeostasis-promoting and anti-inflammatory effects. The potential protective role of SolP is being increasingly 
Table I. Baseline characteristics and plasma sphingolipid metabolite levels of the sex- and body composition-matched study population.

\begin{tabular}{|c|c|c|c|c|c|}
\hline Item & Reference range & Controls $(\mathrm{n}=25)$ & Pre-DM $(n=25)$ & T2DM $(n=25)$ & P-value \\
\hline Female sex $(\%)$ & & $16(64.0 \%)$ & $16(64.0 \%)$ & $16(64.0 \%)$ & 0.999 \\
\hline Age (years) & & $43.80 \pm 10.65$ & $44.24 \pm 13.57$ & $48.76 \pm 11.70$ & 0.335 \\
\hline Cigarette smoking (\%) & & 24 & 28 & 28 & 0.934 \\
\hline Duration of DM (years) & & & & $7.57 \pm 5.93$ & \\
\hline $\mathrm{BF}(\%)$ & & $28.73 \pm 8.39$ & $29.62 \pm 6.13$ & $30.71 \pm 7.76$ & 0.652 \\
\hline LMI (kg/m²) & & $18.06 \pm 1.82$ & $18.12 \pm 1.96$ & $18.14 \pm 1.83$ & 0.982 \\
\hline BMI $\left(\mathrm{kg} / \mathrm{m}^{2}\right)$ & & $24.62 \pm 6.30$ & $26.01 \pm 4.07$ & $26.43 \pm 3.37$ & 0.380 \\
\hline $\mathrm{WC}(\mathrm{cm})$ & & $88.17 \pm 8.66$ & $87.04 \pm 9.52$ & $96.12 \pm 9.63$ & 0.126 \\
\hline $\mathrm{HC}(\mathrm{cm})$ & & $98.67 \pm 6.24$ & $100.25 \pm 7.30$ & $95.35 \pm 7.78$ & 0.501 \\
\hline Central obesity ${ }^{\mathrm{a}}(\%)$ & & 54.2 & 73.9 & 75.0 & 0.255 \\
\hline $\mathrm{SBP}(\mathrm{mmHg})$ & $90-140$ & $116.08 \pm 14.49$ & $117.32 \pm 13.37$ & $127.95 \pm 17.41$ & 0.156 \\
\hline $\mathrm{DBP}(\mathrm{mmHg})$ & $60-90$ & $81.22 \pm 14.26$ & $79.50 \pm 10.12$ & $75.62 \pm 18.04$ & 0.430 \\
\hline HbA1c $(\%)$ & $4-6$ & $5.12 \pm 0.31$ & $5.63 \pm 0.43$ & $8.99 \pm 1.25$ & $<0.001$ \\
\hline FPG (mmol/l) & $3.9-6.1$ & $5.26 \pm 2.20$ & $5.68 \pm 0.68$ & $10.69 \pm 5.05$ & $<0.001$ \\
\hline $\mathrm{UA}(\mu \mathrm{mol} / \mathrm{l})$ & $150-420$ & $333.00 \pm 80.44$ & $430.50 \pm 74.66$ & $299.95 \pm 99.32$ & 0.153 \\
\hline HDL-C (mmol/l) & $1.16-1.42$ & $1.31 \pm 0.34$ & $1.22 \pm 0.57$ & $1.01 \pm 0.45$ & 0.062 \\
\hline LDL-C (mmol/l) & $2.07-3.10$ & $2.68 \pm 0.96$ & $2.79 \pm 0.99$ & $2.56 \pm 0.76$ & 0.685 \\
\hline $\mathrm{TG}(\mathrm{mmol} / \mathrm{l})$ & $0.56-1.47$ & $1.71 \pm 1.07$ & $1.59 \pm 0.73$ & $3.29 \pm 2.08$ & 0.008 \\
\hline $\mathrm{TC}(\mathrm{mmol} / \mathrm{l})$ & $3.1-5.69$ & $4.57 \pm 1.20$ & $4.45 \pm 1.23$ & $4.51 \pm 1.03$ & 0.952 \\
\hline $\operatorname{Cer}\left(\mathrm{x} 10^{-2} \mathrm{ng} / \mathrm{ml}\right)$ & & $6.60 \pm 5.14$ & $4.48 \pm 5.12$ & $5.12 \pm 3.76$ & 0.372 \\
\hline GluCer (ng/ml) & & $1.27 \pm 0.65$ & $1.07 \pm 0.56$ & $1.75 \pm 0.64$ & 0.002 \\
\hline LacCer (ng/ml) & & $0.43 \pm 0.46$ & $0.11 \pm 0.04$ & $0.14 \pm 0.15$ & 0.279 \\
\hline $\mathrm{SM}(\mathrm{ng} / \mathrm{ml})$ & & $53.81 \pm 31.56$ & $31.61 \pm 18.15$ & $43.56 \pm 21.32$ & 0.007 \\
\hline $\mathrm{Sa}(\mathrm{ng} / \mathrm{ml})$ & & $0.48 \pm 0.20$ & $0.35 \pm 0.22$ & $0.35 \pm 0.22$ & 0.001 \\
\hline So $(\mathrm{ng} / \mathrm{ml})$ & & $4.92 \pm 2.32$ & $3.49 \pm 2.17$ & $4.18 \pm 1.42$ & 0.056 \\
\hline $\mathrm{Sa} 1 \mathrm{P}\left(\mathrm{x} 10^{-2} \mathrm{ng} / \mathrm{ml}\right)$ & & $8.59 \pm 2.54$ & $8.43 \pm 2.69$ & $7.99 \pm 2.78$ & 0.747 \\
\hline $\operatorname{So} 1 \mathrm{P}\left(\mathrm{x} 10^{-2} \mathrm{ng} / \mathrm{ml}\right)$ & & $5.62 \pm 4.54$ & $2.34 \pm 1.64$ & $1.93 \pm 1.12$ & $<0.001$ \\
\hline
\end{tabular}

Values are expressed as the mean \pm standard deviation or $\mathrm{n}(\%)$. ${ }^{\mathrm{a} C e n t r a l}$ obesity was defined as $\mathrm{WC} \geq 90 \mathrm{~cm}$ in men and $\geq 85 \mathrm{~cm}$ in women. HbA1c, glycated haemoglobin; FPG, fasting plasma glucose; Cer, ceramide; GluCer, glucosyl ceramide; LacCer, lactosyl ceramide; SM, sphingomyelin; Sa, sphinganine; Sa1P, sphinganine-1-phosphate; So, sphingosine; So1P, sphingosine-1-phosphate; H/LDL-C, high/low-density lipoprotein cholesterol; TC, total cholesterol; TG, triglycerides; UA, uric acid; SBP, systolic blood pressure; DBP, diastolic blood pressure; T2DM, type 2 diabetes mellitus; BF, body fat; BMI, body mass index; LMI, lean mass index; WC, waist circumference; HC, hip circumference.

recognized in the fields of coronary artery disease and diabetes, as well as associated complications, including diabetic nephropathy (23). In the present study, So1P was not only positively associated with the LMI but also with sex. A noteworthy phenomenon is that the SolP concentration in the male controls was two times higher than in the matched female counterparts, but So1P was not associated with age. Consistent results have been reported in the different setting of Alzheimer's disease and the sex-dependent role of SolP has been indicated in certain diseases (24). Females and males have different levels of risk for developing certain diseases. Regarding T2DM, healthy male adults appear to be more susceptible to this disease compared to healthy females who have reached menopause; however, following the onset of DM, the risk for diabetes-associated stroke was elevated in females relative to that in males $(25,26)$. To date, the mechanism for this reversal effect has remained elusive, and it is indicated that sphingolipids, particularly So1P, may be involved in the aforementioned risk alteration due to its sex-dependent role and its fluctuations during diabetes progression. Further cohort studies focusing on dynamic So1P variations are required to validate this hypothesis.

In the present study, three groups (patients with T2DM, pre-DM, and age-, sex- and body composition-matched healthy volunteers) were analyzed to screen the potential significant variables involved in the development of diabetes. Compared with those in the matched healthy controls, the serum levels of GluCer, SM, Sa and So were significantly decreased in pre-DM and DM patients, but remained higher in DM patients compared with those in pre-DM patients. This alteration graphically presented as a ' $U$ ' shape change during the progression of diabetes. These results were in line with several other studies. SM accumulation was identified in the glomeruli of diabetic mice and elevated in the serum of young obese adults (27). Furthermore, increases in adipocyte GluCer were indicated to hinder insulin signaling (28). While a previous study reported 
Table II. Anthropometric data and concentration of sphingolipids in diabetic patients with or without cardiovascular complications.

\begin{tabular}{|c|c|c|c|}
\hline Item & T2DM $(n=53)$ & T2DM+CVD $(n=30)$ & P-value \\
\hline Females/males & $39 / 14$ & $22 / 8$ & 0.999 \\
\hline Age (years) & $52.6 \pm 15.83$ & $58.77 \pm 13.28$ & 0.075 \\
\hline $\mathrm{BF}(\%)$ & $27.61 \pm 6.89$ & $29.21 \pm 8.04$ & 0.341 \\
\hline LMI $\left(\mathrm{kg} / \mathrm{m}^{2}\right)$ & $17.65 \pm 2.19$ & $17.63 \pm 2.23$ & 0.955 \\
\hline BMI $\left(\mathrm{kg} / \mathrm{m}^{2}\right)$ & $24.56 \pm 3.71$ & $25.16 \pm 4.07$ & 0.498 \\
\hline $\mathrm{WC}(\mathrm{cm})$ & $93.24 \pm 9.52$ & $90.70 \pm 9.35$ & 0.353 \\
\hline $\mathrm{HC}(\mathrm{cm})$ & $97.87 \pm 14.99$ & $94.35 \pm 7.64$ & 0.323 \\
\hline Central obesity (\%) & 68.80 & 60.00 & 0.577 \\
\hline $\mathrm{SBP}(\mathrm{mmHg})$ & $128.51 \pm 15.53$ & $153.07 \pm 13.49$ & $<0.001$ \\
\hline $\mathrm{DBP}(\mathrm{mmHg})$ & $77.79 \pm 10.13$ & $189.55 \pm 19.97$ & $<0.001$ \\
\hline HbA1c $(\%)$ & $9.47 \pm 11.14$ & $6.55 \pm 0.97$ & 0.171 \\
\hline FPG (mmol/l) & $9.40 \pm 4.49$ & $6.18 \pm 2.39$ & $<0.001$ \\
\hline 2hPG (mmol/l) & $15.54 \pm 5.04$ & $14.62 \pm 23.41$ & 0.861 \\
\hline $\mathrm{CO}(1 / \mathrm{min})$ & $4.83 \pm 0.44$ & $4.38 \pm 0.58$ & $<0.001$ \\
\hline $\mathrm{EF}(\%)$ & $64.45 \pm 3.72$ & $58.07 \pm 2.81$ & $<0.001$ \\
\hline $\operatorname{Cer}\left(\times 10^{-2} \mathrm{ng} / \mathrm{ml}\right)$ & $5.06 \pm 4.67$ & $4.02 \pm 2.79$ & 0.386 \\
\hline GluCer (ng/ml) & $1.52 \pm 0.65$ & $1.42 \pm 0.53$ & 0.333 \\
\hline LacCer (ng/ml) & $0.13 \pm 0.65$ & $0.12 \pm 0.15$ & 0.801 \\
\hline $\mathrm{SM}(\mathrm{ng} / \mathrm{ml})$ & $38.69 \pm 17.80$ & $28.55 \pm 14.49$ & 0.010 \\
\hline $\mathrm{Sa}(\mathrm{ng} / \mathrm{ml})$ & $0.31 \pm 0.13$ & $0.20 \pm 0.07$ & $<0.001$ \\
\hline So (ng/ml) & $4.28 \pm 1.58$ & $3.08 \pm 1.27$ & 0.023 \\
\hline $\operatorname{Sa} 1 \mathrm{P}\left(\mathrm{x} 10^{-2} \mathrm{ng} / \mathrm{ml}\right)$ & $7.25 \pm 1.77$ & $6.40 \pm 2.04$ & 0.028 \\
\hline So1P $\left(\times 10^{-2} \mathrm{ng} / \mathrm{ml}\right)$ & $2.56 \pm 1.72$ & $0.85 \pm 0.44$ & 0.024 \\
\hline
\end{tabular}

Values are expressed as the mean \pm standard deviation or $\mathrm{n}(\%)$. T2DM + CVD, T2DM with cardiovascular complications group. HbA1c, glycated haemoglobin; CO, cardiac output; EF, ejection fraction; 2hPG, 2-h plasma glucose; FPG, fasting plasma glucose; Cer, ceramide; GluCer, glucosyl ceramide; LacCer, lactosyl ceramide; SM, sphingomyelin; Sa, sphinganine; Sa1P, sphinganine-1-phosphate; So, sphingosine; So1P, sphingosine-1-phosphate; SBP, systolic blood pressure; DBP, diastolic blood pressure; T2DM, type 2 diabetes mellitus; BF, body fat; BMI, body mass index; LMI, lean mass index; WC, waist circumference; HC, hip circumference.

Table III. ORs of potential sphingolipid biomarkers for T2DM with cardiovascular complications.

\begin{tabular}{|c|c|c|c|c|c|c|c|c|}
\hline \multirow[b]{2}{*}{ Substance } & \multirow[b]{2}{*}{$\beta$} & \multicolumn{3}{|c|}{ Unadjusted } & \multirow[b]{2}{*}{$\beta$} & \multicolumn{3}{|c|}{ Adjusted } \\
\hline & & P-value ${ }^{a}$ & OR & $95 \% \mathrm{CI}$ & & P-value ${ }^{b}$ & OR & $95 \% \mathrm{CI}$ \\
\hline SM & -0.025 & 0.015 & 0.975 & $0.925-0.991$ & 0.003 & 0.116 & 1.003 & 0.999-1.009 \\
\hline $\mathrm{Sa}$ & -0.014 & $<0.001$ & 0.986 & 0.979-0.994 & -0.023 & 0.027 & 0.977 & $0.957-0.997$ \\
\hline So & 0 & 0.027 & 1.000 & 0.999-1.000 & 0.001 & 0.311 & 1.001 & 0.999-1.002 \\
\hline So1P & -0.170 & 0.018 & 0.844 & $0.733-0.971$ & -0.263 & 0.045 & 0.769 & $0.549-0.995$ \\
\hline
\end{tabular}

${ }^{a} \mathrm{P}$-value was calculated by univariate logistic regression analysis. ${ }^{\mathrm{b}} \mathrm{P}$-value was calculated by multivariate logistic regression analysis after adjustment for SM, Sa, So, Sa1P and So1P. SM, sphingomyelin; Sa, sphinganine; Sa1P, sphinganine-1-phosphate; So, sphingosine; So1P, sphingosine-1-phosphate; OR, odds ratio.

that Sa was elevated in T2DM patients compared with that in healthy controls (29), the opposite result was observed in the present study. The size of the study population, the type of blood sample and sex distribution may partially contribute to this controversial observation.

Most importantly, So1P was inversely associated with the progression of diabetes. It gradually decreased in patients with
pre-DM compared with that in the controls, and decreased further in diabetic patients. It is rational to expect that the protective effect of So1P ceases when individuals progress from pre-DM to diabetes. The underlying mechanism may in part be that So1P regulates the maturation and function of pancreatic $\beta$-cells (30). SolP phosphatases, which partly control intracellular So1P metabolism, were recently identified 

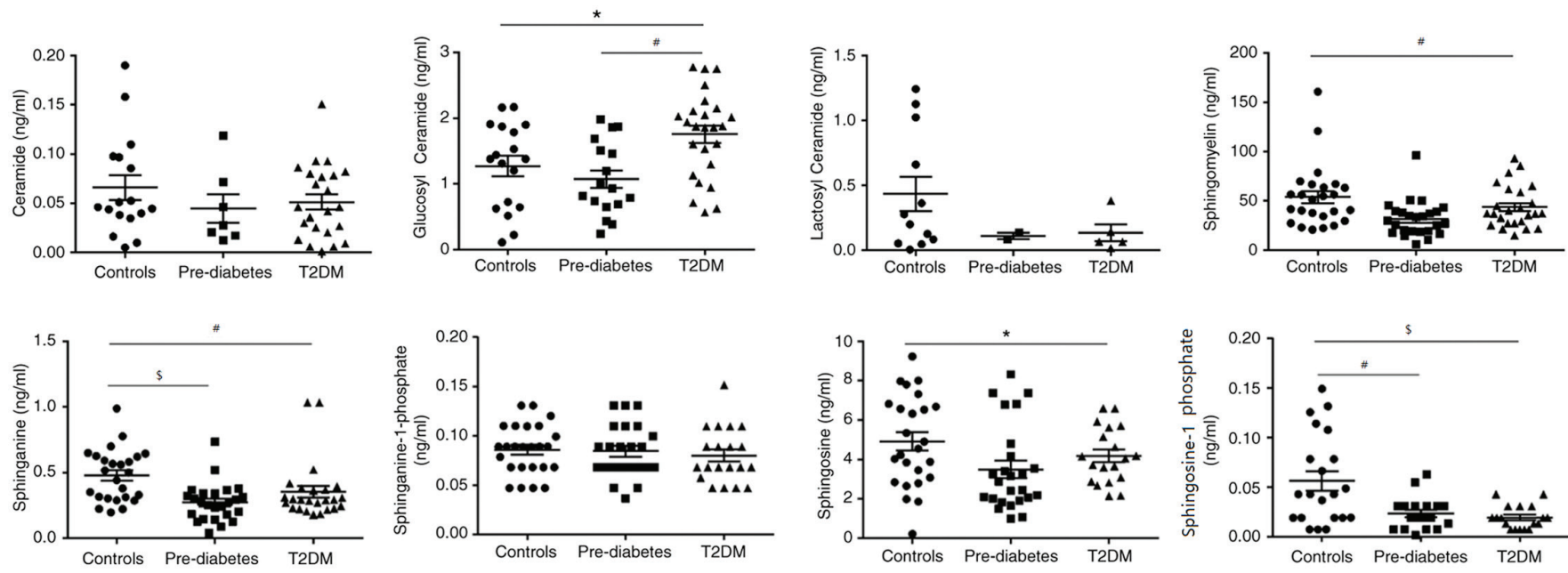

Figure 5. Dynamic changes in the sphingolipid metabolic profile during progression from a healthy condition to Pre-DM, and then to T2DM. Glucosyl ceramide, ${ }^{\prime \prime} \mathrm{P}<0.01, \mathrm{~T} 2 \mathrm{DM}$ vs. Pre-DM and ${ }^{*} \mathrm{P}<0.05$, T2DM vs. Controls; sphingosine- 1 phosphate, ${ }^{\mathrm{S}} \mathrm{P}<0.001$, Controls vs. T2DM and ${ }^{\#} \mathrm{P}<0.01$, Controls vs. Pre-DM; sphinganine, ${ }^{\#} \mathrm{P}<0.01$, Controls vs. T2DM, and ${ }^{\$} \mathrm{P}<0.001$, Controls vs. Pre-DM; sphingomyelin, ${ }^{\#} \mathrm{P}<0.01$, Controls vs. T2DM; and Sphingosine, "P $<0.05$, Controls vs. T2DM. DM, diabetes mellitus; T2DM, type $2 \mathrm{DM}$
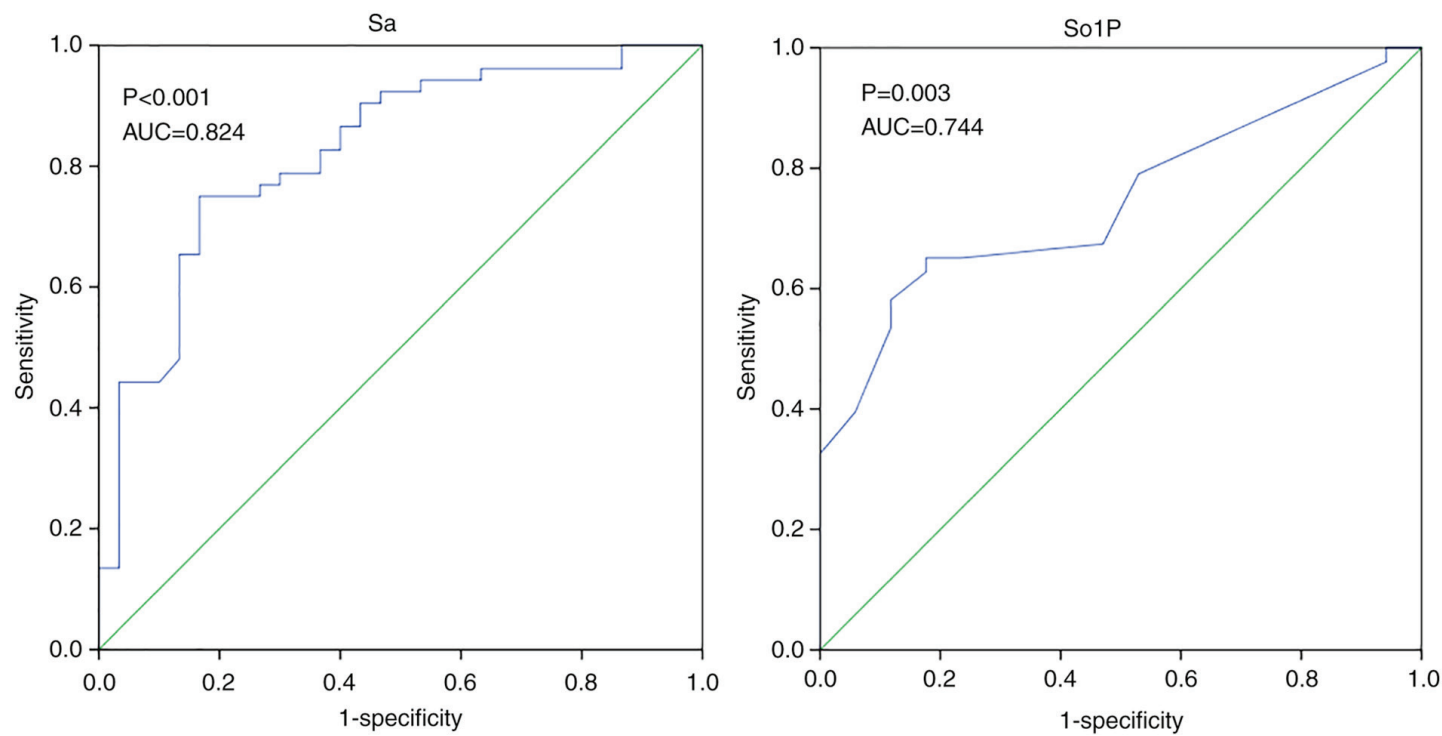

Figure 6. ROC analysis among diabetic patients with and without cardiovascular complications. AUC, area under the ROC curve; ROC, receiver operating characteristic; Sa, sphinganine; So1P, sphingosine-1-phosphate.

to be critical for $\beta$-cell endoplasmic reticulum stress, which may further cause $\beta$-cell dysfunction and accelerate the development of diabetes (31).

It has been established that SolP influences cell behavior and several human diseases, including diabetes, obesity and $\mathrm{CVD}$, at the cytosolic and the nuclear level. Aberration of sphingolipids in human blood samples was confirmed and linked to future cardiovascular events (32). In this context, the present aimed to determine whether SolP may serve as a biomarker for predicting the severity of diabetes. Multivariate regression analysis was applied, revealing that So1P and Sa were two independent variables that were significantly different between diabetic patients and diabetic patients with CVD. ROC analysis also indicated that they were able to differentiate between diabetic patients with CVD and those without cardiovascular complications. However, SolP was not associated with glucose control reflected by HbAlc. Thus, it may be proposed that SolP is a biomarker for evaluating the risk of developing diabetes-associated CVD in patients with T2DM.

Inflammation may explain the strong association between CVD and T2DM. Evidence has been presented for the involvement of SolP in the modulation of regulatory $\mathrm{T}$ cells, which are essential for inflammatory and autoimmune diseases (33). In addition, infiltration of $\mathrm{CD} 8^{+} \mathrm{T}$ cells and macrophages, which have a role in the initiation and formation of atherosclerotic plaques and even the fate of unstable plaques, may result from SolP-mediated signaling (34). Conversely, SolP signaling is directly involved in vascular development through the Rho/Rho-associated protein kinase and PI3K/AKT 
Table IV. Baseline characteristics of T2DM population stratified by HbA1c.

\begin{tabular}{|c|c|c|c|c|c|}
\hline \multirow[b]{2}{*}{ Item } & \multirow[b]{2}{*}{ Total } & \multicolumn{3}{|c|}{ HbA1c $(\%)$} & \multirow[b]{2}{*}{ P-value } \\
\hline & & $>9$ & $7-9$ & $<7$ & \\
\hline $\mathrm{N}$ & 94 & 31 & 31 & 32 & \\
\hline Female sex $(\%)$ & $61(64.9 \%)$ & $24(77.4 \%)$ & $16(51.6 \%)$ & $21(65.6 \%)$ & 0.103 \\
\hline Age (years) & $54.62 \pm 14.13$ & $50.48 \pm 11.00$ & $54.97 \pm 15.51$ & $58.28 \pm 14.79$ & 0.089 \\
\hline $\mathrm{BF}(\%)$ & $29.14 \pm 7.41$ & $26.17 \pm 6.04$ & $31.84 \pm 7.94$ & $29.31 \pm 7.20$ & 0.010 \\
\hline LMI (kg/m²) & $17.33 \pm 2.05$ & $17.58 \pm 1.83$ & $17.29 \pm 2.04$ & $17.15 \pm 2.28$ & 0.707 \\
\hline BMI $\left(\mathrm{kg} / \mathrm{m}^{2}\right)$ & $24.65 \pm 3.42$ & $23.92 \pm 2.79$ & $25.53 \pm 3.08$ & $24.49 \pm 4.10$ & 0.172 \\
\hline $\mathrm{WC}(\mathrm{cm})$ & $93.20 \pm 10.70$ & $90.03 \pm 10.00$ & $95.07 \pm 10.03$ & $94.35 \pm 11.81$ & 0.382 \\
\hline $\mathrm{HC}(\mathrm{cm})$ & $97.73 \pm 15.24$ & $89.40 \pm 23.03$ & $102.07 \pm 7.13$ & $101.26 \pm 7.13$ & 0.033 \\
\hline Central obesity (\%) & 70.2 & 60.0 & 80.0 & 70.6 & 0.488 \\
\hline $\mathrm{SBP}(\mathrm{mmHg})$ & $129.65 \pm 17.70$ & $126.59 \pm 15.16$ & $129.57 \pm 16.14$ & $132.70 \pm 21.29$ & 0.419 \\
\hline $\mathrm{DBP}(\mathrm{mmHg})$ & $79.01 \pm 11.69$ & $79.48 \pm 12.88$ & $79.00 \pm 9.95$ & $78.57 \pm 12.46$ & 0.957 \\
\hline HbA1c $(\%)$ & $8.63 \pm 2.27$ & $11.17 \pm 1.91$ & $8.35 \pm 0.43$ & $6.51 \pm 0.60$ & $<0.001$ \\
\hline FPG (mmol/l) & $9.43 \pm 4.41$ & $13.02 \pm 4.36$ & $8.35 \pm 0.43$ & $6.46 \pm 0.60$ & $<0.001$ \\
\hline $\mathrm{UA}(\mu \mathrm{mol} / \mathrm{l})$ & $311.38 \pm 84.10$ & $298.30 \pm 70.40$ & $340.47 \pm 99.20$ & $296.00 \pm 78.96$ & 0.130 \\
\hline HDL-C (mmol/l) & $0.95 \pm 0.34$ & $1.00 \pm 0.27$ & $0.89 \pm 0.44$ & $0.96 \pm 0.27$ & 0.417 \\
\hline LDL-C (mmol/l) & $2.59 \pm 0.92$ & $2.57 \pm 0.97$ & $2.59 \pm 0.89$ & $2.61 \pm 0.93$ & 0.989 \\
\hline $\mathrm{TG}(\mathrm{mmol} / \mathrm{l})$ & $2.32 \pm 2.25$ & $1.97 \pm 1.25$ & $1.90 \pm 1.37$ & $3.11 \pm 3.36$ & 0.068 \\
\hline $\mathrm{TC}(\mathrm{mmol} / \mathrm{l})$ & $4.36 \pm 1.10$ & $4.24 \pm 1.12$ & $4.27 \pm 1.12$ & $4.57 \pm 1.08$ & 0.462 \\
\hline
\end{tabular}

Values are expressed as the mean \pm standard deviation or $\mathrm{n}(\%)$. T2DM $+\mathrm{CAD}, \mathrm{T} 2 \mathrm{DM}$ with cardiovascular complication group. HbA1c, glycated haemoglobin; FPG, fasting plasma glucose; SBP, systolic blood pressure; DBP, diastolic blood pressure; T2DM, type 2 diabetes mellitus; BF, body fat; BMI, body mass index; LMI, lean mass index; WC, waist circumference; HC, hip circumference; H/LDL-C, high/low-density lipoprotein cholesterol; TC, total cholesterol; TG, triglycerides; UA, uric acid.

pathways $(35,36)$. Compared with So1P, Sa is relatively poorly investigated in the fields of diabetes and CVD. Thus, there is a demand for further studies into the mechanism of $\mathrm{Sa}$ in the progression of T2DM.

In terms of limitations, the present study is a single-center study and the cohort is relatively small. Further study on the roles of So1P alterations, specifically in females and males with diabetes and diabetes-associated cardiovascular disease, is required to validate the mechanism of the risk. It remains elusive whether So1P is associated with the duration of diabetes and severity of atherosclerosis in diabetic patients. Studies using larger cohorts with more detailed stage stratification may improve the current knowledge regarding sphingolipids in diabetes.

In conclusion, the present study indicated that the serum levels of So1P, SM, Sa and So are significantly decreased in patients with pre-DM and diabetes compared with those in healthy controls. So1P is significantly correlated with the progression of T2DM, and, along with Sa, represents a potential biomarker for predicting an elevated risk of cardiovascular complications.

\section{Acknowledgements}

The authors appreciate the help of Dr Xiaoli Yao (Department of Endocrinology, The First Affiliated Hospital of Xi'an Jiaotong University, Xi'an, China) for helpful suggestions and review of the manuscript.

\section{Funding}

The current study was supported by grants from the National Science Foundation of China (grant no. 81500690 to YW), the First Affiliated Hospital of Xi'an Jiaotong University (grant no. 2013YK20), the Clinical Research Award of the First Affiliated Hospital of Xi'an Jiaotong University (grant no. XJTU1AF-CRF-2016-016) and the Chinese Medical Association (grant no. 13040470432).

\section{Availability of data and materials}

The datasets used and/or analyzed during the present study are available from the corresponding author on reasonable request.

\section{Authors' contributions}

JS, MH and YW performed the experiments and analyzed the data; JS and BS designed and supervised the study; JS drafted the manuscript. YH and XZ collected the data and performed the statistical analyses. JS and BS interpreted the data. All authors read and approved the final manuscript.

\section{Ethics approval and consent to participate}

The present study complied with the Declaration of Helsinki and was approved by the Ethics Committees of the First Affiliated Hospital of Xi'an Jiaotong University (Xi'an, China). 
Participants enrolled in the present study were given the consent form and provided written informed consent.

\section{Patient consent for publication}

Not applicable.

\section{Competing interests}

The authors declare that they have no competing interests.

\section{References}

1. Mathers CD and Loncar D: Projections of global mortality and burden of disease from 2002 to 2030. PLoS Med 3: e442, 2006.

2. Wong ND: Epidemiological studies of CHD and the evolution of preventive cardiology. Nat Rev Cardiol 11: 276-289, 2014.

3. American Diabetes Association: 10. Cardiovascular disease and risk management: Standards of Medical Care in Diabete-2019. Diabetes Care 42 (Suppl 1): S103-S123, 2019.

4. Tonks KT, Coster AC, Christopher MJ, Chaudhuri R, Xu A, Gagnon-Bartsch J, Chisholm DJ, James DE, Meikle PJ, Greenfield JR and Samocha-Bonet D: Skeletal muscle and plasma lipidomic signatures of insulin resistance and overweight/obesity in humans. Obesity (Silver Spring) 24: 908-916, 2016.

5. Chaurasia B, Kaddai VA, Lancaster GI, Henstridge DC, Sriram S, Galam DL, Gopalan V, Prakash KN, Velan SS, Bulchand $\mathrm{S}$, et al: Adipocyte ceramides regulate subcutaneous adipose browning, inflammation, and metabolism. Cell Metab 24: 820-834, 2016.

6. Meikle PJ and Summers SA: Sphingolipids and phospholipids in insulin resistance and related metabolic disorders. Nat Rev Endocrinol 13: 79-91, 2017.

7. Samad F, Badeanlou L, Shah C and Yang G: Adipose tissue and ceramide biosynthesis in the pathogenesis of obesity. Adv Exp Med Biol 721: 67-86, 2011.

8. Holland WL, Bikman BT, Wang LP, Yuguang G, Sargent KM, Bulchand S, Knotts TA, Shui G, Clegg DJ, Wenk MR, et al: Lipid-induced insulin resistance mediated by the proinflammatory receptor TLR4 requires saturated fatty acid-induced ceramide biosynthesis in mice. J Clin Invest 121: 1858-1870, 2011.

9. Holland WL, Miller RA, Wang ZV, Sun K, Barth BM, Bui HH, Davis KE, Bikman BT, Halberg N, Rutkowski JM, et al: Receptor-mediated activation of ceramidase activity initiates the pleiotropic actions of adiponectin. Nat Med 17: 55-63, 2011.

10. Rauch BH: Sphingosine 1-phosphate as a link between blood coagulation and inflammation. Cell Physiol Biochem 34: 185-96, 2014.

11. Soltau I, Mudersbach E, Geissen M, Schwedhelm E, Winkler MS, Geffken M, Peine S, Schoen G, Debus ES, Larena-Avellaneda A and Daum G: Serum-sphingosine-1-phosphate concentrations are inversely associated with atherosclerotic diseases in humans. PLoS One 11: e0168302, 2016.

12. Joint Committee for Developing Chinese guidelines on Prevention and Treatment of Dyslipidemia in Adults: Chinese guidelines on prevention and treatment of dyslipidemia in adults. Zhonghua Xin Xue Guan Bing Za Zhi 35: 390-419, 2007 (In Chinese).

13. Zhou BF; Cooperative Meta-Analysis Group of the Working Group on Obesity in China: Predictive values of body mass index and waist circumference for risk factors of certain related diseases in Chinese adults-study on optimal cut-off points of body mass index and waist circumference in Chinese adults. Biomed Environ Sci 15: 83-96, 2002.

14. Gómez-Ambrosi J, Silva C, Catalán V, Rodríguez A, Galofré JC, Escalada J, Valentí V, Rotellar F, Romero S, Ramírez B, et al: Clinical usefulness of a new equation for estimating body fat. Diabetes Care 35: 383-388, 2012.

15. Grammatikos G, Schoell N, Ferreirós N, Bon D, Herrmann E, Farnik H, Köberle V, Piiper A, Zeuzem S, Kronenberger B, et al: Serum sphingolipidomic analyses reveal an upregulation of C16-ceramide and sphingosine-1-phosphate in hepatocellular carcinoma. Oncotarget 7: 18095-18105, 2016.

16. Haus JM, Kashyap SR, Kasumov T, Zhang R, Kelly KR, Defronzo RA and Kirwan JP: Plasma ceramides are elevated in obese subjects with Type 2 diabetes and correlate with the severity of insulin resistance. Diabetes 58: 337-343, 2009.
17. Yaghobian D, Don AS, Yaghobian S, Chen X, Pollock CA and Saad S: Increased sphingosine 1-phosphate mediates inflammation and fibrosis in tubular injury in diabetic nephropathy. Clin Exp Pharmacol Physiol 43: 56-66, 2016.

18. Egom EE, Mamas MA, Chacko S, Stringer SE, Charlton-Menys V, El-Omar M, Chirico D, Clarke B, Neyses L, Cruickshank JK, et al: Serum sphingolipids level as a novel potential marker for early detection of human myocardial ischaemic injury. Front Physiol 4: 130, 2013.

19. Sasset L, Zhang Y, Dunn TM and Di Lorenzo A: Sphingolipid de novo biosynthesis: A rheostat of cardiovascular homeostasis. Trends Endocrinol Metab 27: 807-819, 2016.

20. Mi S, Zhao YY, Dielschneider RF, Gibson SB and Curtis JM: An LC/MS/MS method for the simultaneous determination of individual sphingolipid species in B cells. J Chromatogr B Analyt Technol Biomed Life Sci 1031: 50-60, 2016.

21. Turpin SM, Nicholls HT, Willmes DM, Mourier A, Brodesser S, Wunderlich CM, Mauer J, Xu E, Hammerschmidt P, Brönneke HS, et al: Obesity-induced CerS6-dependent C16:0 ceramide production promotes weight gain and glucose intolerance. Cell Metab 20: 678-686, 2014.

22. Boini KM, Zhang C, Xia M, Poklis JL and Li PL: Role of sphingolipid mediator ceramide in obesity and renal injury in mice fed a high-fat diet. J Pharmacol Exp Ther 334: 839-846, 2010.

23. Awad AS, Rouse MD, Khutsishvili K, Huang L, Bolton WK, Lynch KR and Okusa MD: Chronic sphingosine 1-phosphate 1 receptor activation attenuates early-stage diabetic nephropathy independent of lymphocytes. Kidney Int 79: 1090-1098, 2011.

24. Mielke MM, Haughey NJ, Han D, An Y, Bandaru VVR, Lyketsos CG, Ferrucci L and Resnick SM: The association between plasma ceramides and sphingomyelins and risk of Alzheimer's disease differs by sex and APOE in the baltimore longitudinal study of aging. J Alzheimers Dis 60: 819-828, 2017.

25. Gale EA and Gillespie KM: Diabetes and sex. Diabetologia 44: 3-15, 2001.

26. Peters SA, Huxley RR and Woodward M: Diabetes as a risk factor for stroke in women compared with men: A systematic review and meta-analysis of 64 cohorts, including 775,385 individuals and 12,539 strokes. Lancet 383: 1973-1980, 2014.

27. Miyamoto S, Hsu CC, Hamm G, Darshi M, Diamond-Stanic M, Declèves AE, Slater L, Pennathur S, Stauber J, Dorrestein PC and Sharma K: Mass spectrometry imaging reveals elevated glomerular ATP/AMP in diabetes/obesity and identifies sphingomyelin as a possible mediator. EBioMedicine 7: 121-134, 2016.

28. Chavez JA, Siddique MM, Wang ST, Ching J, Shayman JA and Summers SA: Ceramides and glucosylceramides are independent antagonists of insulin signaling. J Biol Chem 289: 723-734, 2014.

29. Górska M, Dobrzyń A and Baranowski M: Concentrations of sphingosine and sphinganine in plasma of patients with Type 2 diabetes. Med Sci Monit 11: CR35-CR38, 2005.

30. Rütti S, Ehses JA, Sibler RA, Prazak R, Rohrer L, Georgopoulos S, Meier DT, Niclauss N, Berney T, Donath MY and von Eckardstein A: Low- and high-density lipoproteins modulate function, apoptosis, and proliferation of primary human and murine pancreatic beta-cells. Endocrinology 150: 4521-4530, 2009.

31. Taguchi Y, Allende ML, Mizukami H, Cook EK, Gavrilova O, Tuymetova G, Clarke BA, Chen W, Olivera A and Proia RL: Sphingosine-1-phosphate phosphatase 2 regulates pancreatic islet beta-cell endoplasmic reticulum stress and proliferation. J Biol Chem 291: 12029-12038, 2016.

32. Alshehry ZH, Mundra PA, Barlow CK, Mellett NA, Wong G, McConville MJ, Simes J, Tonkin AM, Sullivan DR, Barnes EH, et al: Plasma lipidomic profiles improve on traditional risk factors for the prediction of cardiovascular events in type 2 diabetes mellitus. Circulation 134: 1637-1650, 2016.

33. Liu G, Yang K, Burns S, Shrestha S and Chi H: The S1P (1)-mTOR axis directs the reciprocal differentiation of T (H)1 and T (reg) cells. Nat Immunol 11: 1047-1056, 2010.

34. Nishimura S, Manabe I, Nagasaki M, Eto K, Yamashita $H$, Ohsugi M, Otsu M, Hara K, Ueki K, Sugiura S, et al. CD8 ${ }^{+}$effector $\mathrm{T}$ cells contribute to macrophage recruitment and adipose tissue inflammation in obesity. Nat Med 15: 914-920, 2009.

35. Murakami A, Takasugi H, Ohnuma S, Koide Y, Sakurai A, Takeda S, Hasegawa T, Sasamori J, Konno T, Hayashi K, et al: Sphingosine 1-phosphate (S1P) regulates vascular contraction via S1P3 receptor: Investigation based on a new S1P3 receptor antagonist. Mol Pharmacol 77: 704-713, 2010.

36. Nofer JR, van der Giet M, Tölle M, Wolinska I, von Wnuck Lipinski K, Baba HA, Tietge UJ, Gödecke A, Ishii I, Kleuser B, et al: HDL induces NO-dependent vasorelaxation via the lysophospholipid receptor S1P3. J Clin Invest 113: 569-581, 2004. 